\title{
A sustainable programme to prevent falls and near falls in community dwelling older people: results of a randomised trial
}

\author{
Margaret Steinberg, Colleen Cartwright, Nancye Peel, Gail Williams
}

\begin{abstract}
Study objective-In the causative mechanism of falls among older community dwellers, slips and trips have been found to be significant precursors. The purpose of the two year trial was to assess the effectiveness of multi-component interventions targeting major risk factors for falls in reducing the incidence of slips, trips and falls among the well, older community.

Design-Four groups with approximately equal numbers of participants were randomly allocated to interventions. The prevention strategies included education and awareness raising of falls risk factors, exercise sessions to improve strength and balance, home safety advice to modify environmental hazards, and medical assessment to optimise health. The interventions combined the strategies in an add on approach. The first intervention group receiving the information session only was regarded as the control. The outcome of interest was the occurrence of a slip, trip or fall, monitored prospectively using a daily calendar diary.
\end{abstract}

Participants and setting-Two hundred and fifty two members of the National Seniors Association in the Brisbane district agreed to participate. National Seniors clubs provide a forum for active, community dwelling Australians aged 50 and over to participate in policy, personal development and recreation.

Main results-Using Cox's proportional hazards regression model, adjusted hazard ratios comparing intervention groups with the control ranged from 0.35 (95\% CI $0.17,0.73)$ to $0.48(0.25,0.91)$ for slips; 0.29 $(0.16,0.51)$ to $0.45(0.27,0.74)$ for trips; and $0.60(0.36,1.01)$ to $0.82(0.51,1.31)$ for falls. While calendar monitoring recorded outcome, it was also assessed as a prevention strategy by comparing the intervention groups with a hypothetical nonintervened group. At one year after intervention, reductions in the probability of slips, trips and falls $(61(95 \%$ CI 54,66$) \%$; $56(49,63) \% ; 29(22,36) \%$ respectively) were demonstrated.

Conclusions-This study makes an important contribution to the priority community health issue of falls prevention by showing that effective, sustainable, low cost programmes can be introduced through community-based organisations to reduce the incidence of slips, trips and falls in well, older people.

(F Epidemiol Community Health 2000;54:227-232)

Falls among older people are a target for public health preventive efforts because they are relatively common, carry a significant burden of morbidity and mortality, affect lifestyle choices, are a high cost to the community, and are potentially preventable. ${ }^{1}$

The most common circumstances leading to falls reported by community dwelling older people are slips and trips. ${ }^{2}{ }^{3}$ It has been proposed that there is a continuum from slips and trips, where balance is regained, through near falls to completed falls, when balance is lost. ${ }^{4}$ While falls among older adults have been studied extensively, there are no comparable data on the incidence of slips and trips (or near fall experiences) in this age group, nor has prevention of such incidents been the subject of investigation. ${ }^{5}$

Numerous studies, as detailed in literature reviews ${ }^{67}$ have revealed that falls in older people are complex events involving a number of interactive factors. Risk factors that have been associated with falls include decline in physical functioning, medication use, impairments to the sensory-nervous system, disorders of the musculoskeletal system, and specific chronic diseases. Environmental hazards, social and behavioural factors may also predispose older people to falls. A history of falling is a significant risk factor for future falls, while multiple stumbles (without a fall) are also an independent predictor of subsequent falls. ${ }^{8}$

While the pre-disposing causes and circumstances of falls are different for persons of varying age, health status and level of mobility, extrinsic or environmental factors have been implicated as greater risk factors for the 60 to 74 age group, with intrinsic or disease related factors being more common causes of falls in the 75 and over age group. ${ }^{9}$ The classification of falls according to the predominance of intrinsic or extrinsic factors in fall aetiology is designed to identify appropriate groups for targeting interventions. ${ }^{9}$

Falls intervention programmes aim to reduce the risk of falling by minimising the effect of, or exposure to, any putative risk factor for falling. ${ }^{10}$ In particular, environmental and behavioural risk factors for falls and near falls in the older community are seen as potentially correctable. ${ }^{11}$ Multifactorial intervention programmes have included education designed to increase awareness of risk factors, exercise to 
improve strength and balance, home safety assessment with modification of environmental hazards, and clinical management for optimisation of health. ${ }^{10}$

A review of randomised controlled trials, Interventions to reduce the incidence of falling in the elderly, ${ }^{10}$ showed that few published studies have examined multi-component falls prevention interventions among well, older community dwellers, rather than those at established risk of falling. In addition, few, if any, examined the efficacy of preventing near fall experiences, nor considered that data collection using a diary may, of itself, be a significant intervention.

The study reported in this paper examined these issues. It assessed the effectiveness of multi-component interventions targeting major risk factors for falls in reducing the incidence of slips, trips and falls among well, older community dwellers. The method of analysis also allowed the examination of diary monitoring as an intervention.

\section{Methods}

Ethical clearance for the study was obtained from the Behavioural and Social Sciences Ethical Review Committee of the University of Queensland.

\section{SUBJECTS}

Two hundred and fifty two members from 10 branches of the National Seniors Association in the Brisbane Metropolitan region were recruited to the study. Approximately a third of those who attended the meetings volunteered to participate. National Seniors represent a community group of active Australians aged 50 and over, providing a forum for participation in policy, personal development and recreation.

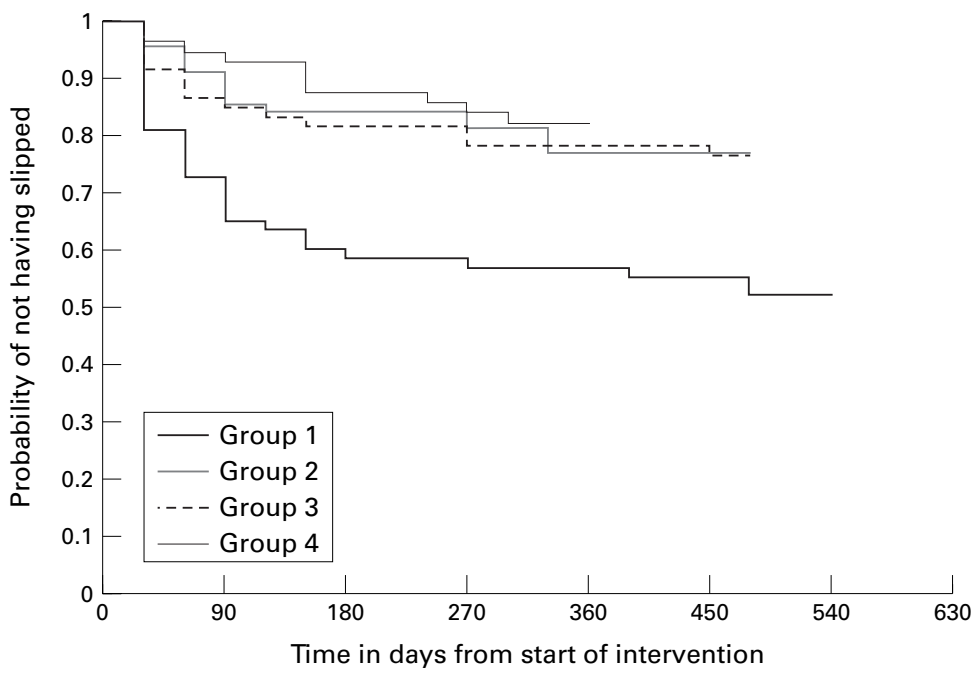

$\begin{array}{lccc} & \text { Hazard ratio } & 95 \% \mathrm{Cl} & \mathrm{p} \text { value } \\ \text { Group 1 (reference) } & 1 & & \\ \text { Group 2 } & 0.43 & 0.22,0.81 & 0.009 \\ \text { Group 3 } & 0.48 & 0.25,0.91 & 0.026 \\ \text { Group 4 } & 0.35 & 0.17,0.73 & 0.005 \\ \text { Groups 2 to 4 (combined) } & 0.42 & 0.26,0.69 & <0.001\end{array}$

Figure 1 Time to first slip stratified by intervention group.
There were no specific exclusion criteria. It was assumed that members who attended National Seniors meetings were capable of giving voluntary consent to participate, met the age limits of the study (over 50 years of age), and had the capacity to understand and comply with the requirements of the project.

SAMPLE SIZE

A sample size of 65 to 70 per group was required to demonstrate with 80 per cent power and at 95 per cent confidence levels, a halving in the proportion of the group experiencing an event. As no data were available on prevalence of slips and trips, a rate of 50 per cent was assumed. Maintaining the sample size of approximately 250 subjects, the same power and confidence levels could detect a 33 per cent reduction in the fall rate from a prevalence of 35 per cent, if the ratio of unexposed (control) to exposed (intervened) was one to three.

\section{INTERVENTIONS}

Four groups with approximately equal numbers of participants were formed by combining two or three National Seniors branches, and the groups were randomly allocated to receive the four interventions. The prevention strategies included education and awareness raising of falls risk factors, exercise sessions designed to improve strength and balance, home safety advice, and medical assessment. The multiple risk factor interventions were implemented at branch level, using where possible, available government and community resources (such as Home Assist/Secure).

The interventions combined the strategies in an "add on" approach. The first intervention group (the control) received an oral presentation, with video on home safety and a pamphlet on falls risk factors and prevention. The second intervention group was offered, in addition, a one hour exercise class once a month, with the use of exercise handouts and a gentle exercise video encouraged between classes. In addition to the presentation and exercise classes, the third intervention group was offered a home safety assessment with financial and practical assistance to make home modifications. For the fourth group, participants were offered a clinical assessment and advice on medical risk factors for falls, as well as the other three components.

\section{DEFINITIONS}

For the purposes of the study, a slip was defined as occurring when the foot slides from underneath the person, while a trip involves a stumble when an object obstructs the pathway. In either case, the balance is regained and the person does not hit the ground. A fall was defined as occurring when the person loses their balance causing them to hit the ground or other object at lower level.

\section{OUTCOME MEASURED}

The outcome of interest was the occurrence of an event (for each of slips, trips or falls). Slips, trips and falls were monitored prospectively 
using a daily calendar diary to minimise recall bias. As many falls among the older community are unwitnessed and do not require medical attention, such self report is an essential source of data. ${ }^{12}$

\section{DATA COLLECTION}

All participants kept a calendar to record daily any slip, trip or fall. For each day of the month, the calendar was marked with a tick, if no incident occurred, or an S (for slip), $\mathrm{T}$ (for trip), or

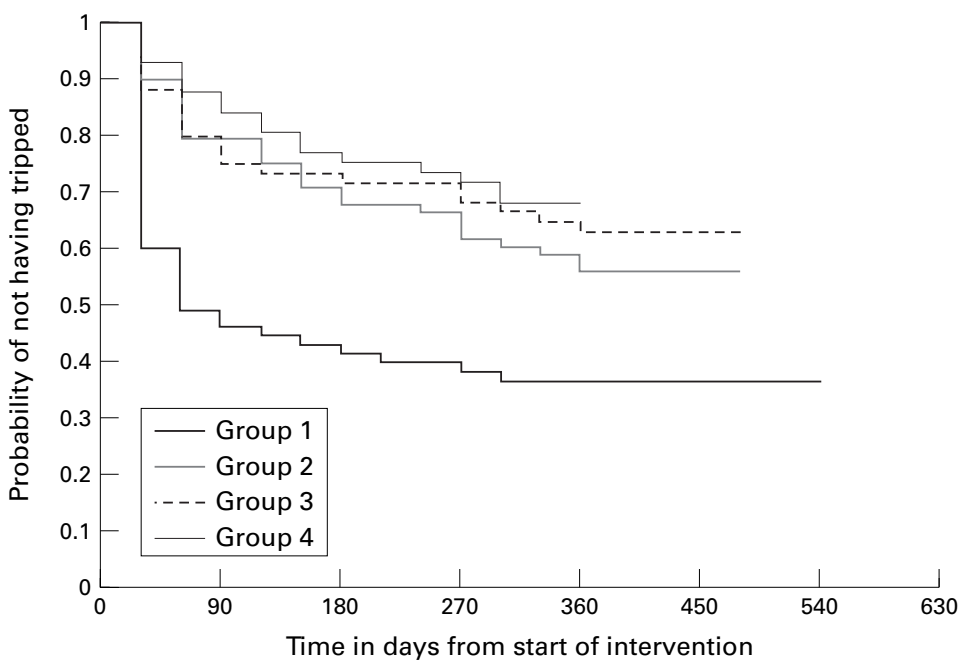

$\begin{array}{lccc} & \text { Hazard ratio } & 95 \% \mathrm{Cl} & \mathrm{p} \text { value } \\ \text { Group 1 (reference) } & 1 & & \\ \text { Group 2 } & 0.45 & 0.27,0.74 & 0.002 \\ \text { Group 3 } & 0.35 & 0.21,0.59 & <0.001 \\ \text { Group 4 } & 0.29 & 0.16,0.51 & <0.001 \\ \text { Groups 2 to 4 (combined) } & 0.36 & 0.24,0.54 & <0.001\end{array}$

Figure 2 Time to first trip stratified by intervention group.

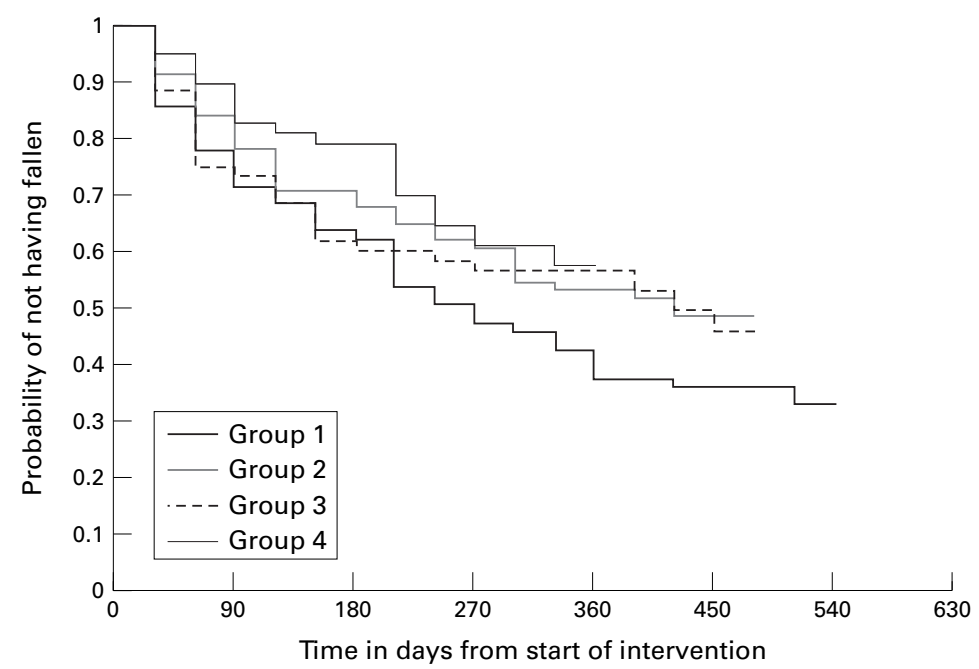

$\begin{array}{lccc} & \text { Hazard ratio } & 95 \% \mathrm{Cl} & \text { p value } \\ \text { Group 1 (reference) } & 1 & & \\ \text { Group 2 } & 0.67 & 0.42,1.07 & 0.092 \\ \text { Group 3 } & 0.82 & 0.51,1.31 & 0.404 \\ \text { Group 4 } & 0.60 & 0.36,1.01 & 0.053 \\ \text { Groups 2 to 4 (combined) } & 0.70 & 0.48,1.01 & 0.058\end{array}$

Figure 3 Time to first fall stratified by intervention group.
F (for fall). Details of any incident were recorded on the back of the monthly sheet, and the record returned at the end of the month. If a record was not received within a fortnight of the end of the month, the participant was contacted by telephone as a reminder.

Any incident was confirmed by telephone, with additional information being gathered at that time, using a standard interview format. Data collected included date, time, place, and circumstances of the slip, trip or fall, together with details of any injury and treatment. All data were self reported. Calendar data were collected for 17 months from April 1996 to August 1997.

At the start of the study, subjects completed a questionnaire to provide baseline information on demographics, falls and medical history, home environment and other possible risk factors for falling. Data were entered in an EPI $\mathrm{INFO}^{13}$ database system.

\section{DATA ANALYSIS}

To assess the effectiveness of interventions, the hypothesis to be tested was that the incidence of slips, trips and falls in intervention groups 2 , 3 and 4 compared with intervention group 1 (the control) would be significantly reduced. A secondary hypothesis was that reductions would be in proportion to the number of strategies used.

Groups were compared with the control for time to first event from the start of intervention, using Kaplan-Meier survival analysis, rather than comparing post-intervention incidence rates by group. The survival analysis model was chosen because preliminary results ${ }^{14}$ suggested changes in incidence rates over time and because many cohort members would experience an event over the study period. Cox's proportional hazards regression model was used to calculate hazard ratios, adjusting for the role of possible confounding variables (age, sex, self reported health, living arrangements and history of slips, trips and falls). Because the intervention components were introduced over a period, time to first event was taken after the start of all components for each intervention, resulting in varying periods of observation post-intervention (see figs 1 to 3 ). A level of 5 per cent was used to determine statistical significance.

While the calendar was designed primarily to record outcome, it was considered that its use might also constitute an intervention in its own right. Qualitative and quantitative evidence at 12 month follow up of the study group suggested that calendar monitoring raised awareness and modified behaviour. ${ }^{14}$ To examine this effect, survival probabilities of the control group and combined intervention groups were compared with a hypothetical reference group. The hypothetical "non-intervened" model projected survival probability, assuming a constant incidence rate based on the incidence for the first three months in the control group for each of slips, trips and falls.

The statistical package EGRET ${ }^{15}$ was used for analysis. 
Results

SUBJECTS

Table 1 shows the characteristics of the subjects by group.

$\chi^{2}$ Tests showed that the differences between groups on the selected risk factors for falls, at baseline, were not statistically significant.

DATA COMPLETENESS

There was 100 per cent return and completion of calendars after telephone follow up. Nine subjects, all women, withdrew over the course of the study because of death or ill health. Two were from the control group, one from intervention 2 , and three each from interventions 3 and 4 . Their results were included in the analysis until the point of censoring except for three subjects (one from intervention 3 and two from intervention 4) who withdrew before the start of all components of the intervention.

COMPARISON OF INTERVENTIONS

Table 2 shows the incidence rates for slips, trips and falls for each group.

Kaplan-Meier survival curves stratified by intervention group are shown in figures 1 to 3 . Hazard ratios comparing groups 2, 3 and 4 with the reference control (Group 1) were adjusted for possible confounding variables. Groups 2 to 4 were also combined to calculate a single hazard ratio compared with control, adjusted for confounders.

In figure 1 , hazard ratios for intervention groups 2,3 and $4(0.43 ; 0.48 ; 0.35$ respectively) compared with the control (reference group 1) for time to first slip, showed that these interventions significantly reduced the risk of slipping. The ratios calculated were adjusted for confounding factors including sex, age

Table 1 Characteristics of subjects by group

\begin{tabular}{|c|c|c|c|c|c|c|}
\hline Characteristic & $\begin{array}{l}\text { Group 1 } \\
(n=63)\end{array}$ & $\begin{array}{l}\text { Group 2 } 2 \\
(n=69)\end{array}$ & $\begin{array}{l}\text { Group } 3 \\
(n=61)\end{array}$ & $\begin{array}{l}\text { Group } 4 \\
(n=59)\end{array}$ & $\begin{array}{l}\text { Total } \\
(n=252)\end{array}$ & $p$ value* \\
\hline \multicolumn{7}{|l|}{ Gender: } \\
\hline female & 78 & 83 & 75 & 81 & 79 & \multirow[t]{2}{*}{0.74} \\
\hline male & 22 & 17 & 25 & 19 & 21 & \\
\hline \multicolumn{7}{|l|}{ Age: } \\
\hline under 75 years & 79 & 67 & 80 & 76 & 75 & \multirow{2}{*}{0.24} \\
\hline 75 years and over & 21 & 33 & 20 & 24 & 25 & \\
\hline \multicolumn{7}{|l|}{ Living: } \\
\hline alone & 41 & 57 & 39 & 49 & 47 & \multirow[t]{2}{*}{0.18} \\
\hline with others & 59 & 43 & 61 & 51 & 53 & \\
\hline \multicolumn{7}{|l|}{ Health: } \\
\hline very good-excellent & 37 & 56 & 34 & 39 & 42 & \multirow{3}{*}{0.16} \\
\hline good & 38 & 28 & 36 & 39 & 35 & \\
\hline \multirow{2}{*}{\multicolumn{7}{|c|}{$\begin{array}{l}\text { farr-poor } \\
\text { History (over previous year): }\end{array}$}} \\
\hline & & & & & & \\
\hline falls & 33 & 43 & 25 & 34 & 34 & 0.12 \\
\hline slips & 41 & 33 & 31 & 32 & 35 & 0.62 \\
\hline trips & 43 & 42 & 43 & 46 & 43 & 0.98 \\
\hline Concerned about falling & 54 & 55 & 61 & 64 & 58 & 0.61 \\
\hline
\end{tabular}

${ }^{\star} \chi^{2}$ tests of differences between groups were not significant at the $\mathrm{p}<0.05$ level. Data shown as percentages.

Table 2 Incidence rates after intervention for slips, trips and falls by group

\begin{tabular}{|c|c|c|c|c|c|}
\hline & & $\begin{array}{l}\text { Group } 1 \\
(n=63)\end{array}$ & $\begin{array}{l}\text { Group } 2 \\
(n=69)\end{array}$ & $\begin{array}{l}\text { Group } 3 \\
(n=60)\end{array}$ & $\begin{array}{l}\text { Group } 4 \\
(n=57)\end{array}$ \\
\hline \multirow[t]{2}{*}{ Slips: } & Incidence rate (events) & $6.77 / 100 \mathrm{pm}$ & $2.55 / 100 \mathrm{pm}$ & $3.62 / 100 \mathrm{pm}$ & $2.91 / 100 \mathrm{pm}$ \\
\hline & Incidence rate (persons) & $2.86 / 100 \mathrm{pm}$ & $1.57 / 100 \mathrm{pm}$ & $1.58 / 100 \mathrm{pm}$ & $1.62 / 100 \mathrm{pm}$ \\
\hline \multirow[t]{2}{*}{ Trips: } & Incidence rate (events) & $23.36 / 100 \mathrm{pm}$ & $12.73 / 100 \mathrm{pm}$ & $11.43 / 100 \mathrm{pm}$ & $8.89 / 100 \mathrm{pm}$ \\
\hline & Incidence rate (persons) & $3.81 / 100 \mathrm{pm}$ & $2.94 / 100 \mathrm{pm}$ & $2.49 / 100 \mathrm{pm}$ & $2.91 / 100 \mathrm{pm}$ \\
\hline \multirow[t]{2}{*}{ Falls: } & Incidence rate (events) & $7.05 / 100 \mathrm{pm}$ & $6.37 / 100 \mathrm{pm}$ & $6.56 / 100 \mathrm{pm}$ & $6.30 / 100 \mathrm{pm}$ \\
\hline & Incidence rate (persons) & $4.00 / 100 \mathrm{pm}$ & $3.43 / 100 \mathrm{pm}$ & $3.62 / 100 \mathrm{pm}$ & $3.88 / 100 \mathrm{pm}$ \\
\hline
\end{tabular}

$\mathrm{pm}=$ person months of observation
KEY POINTS

- Falls and near falls among community dwelling older people are a priority for prevention because of their frequency, associated morbidity and mortality, and cost to the community.

- Few programmes have targeted falls and near falls prevention in well, older community dwellers.

- This randomised trial of falls prevention interventions showed that effective, sustainable, low cost programmes can be introduced through community-based organisations to reduce the incidence of slips, trips and falls.

group (under $75 ; 75$ years and over), health status, living alone, and history of previous slips. While intervention 4 showed the greatest potential for reduction, the hazard ratios did not reduce according to the number of strategies used.

For time to first trip in figure 2, hazard ratios for groups 2,3 and $4(0.45 ; 0.35 ; 0.29$ respectively) compared with the control, showed that these interventions significantly reduced the risk of tripping. The ratios calculated were adjusted for confounding factors previously listed, including history of previous trips. The hazard ratios were in proportion to the number of strategies used, suggesting that protection against the risk of tripping is proportional to the number of components in the intervention.

For time to first fall in figure 3, hazard ratios (adjusted for confounding factors) for groups 2,3 , and $4(0.67 ; 0.82 ; 0.60$ respectively) suggested that the intervention strategies could achieve an 18 to 40 per cent reduction in the risk of falling. While the hazard ratios were not significant, in the case of intervention group 4 with the greatest protective effect, the 95 per cent confidence intervals marginally crossed the null value of one, with a $p$ value of 0.053 .

As the hazard ratios for groups 2, 3 and 4 compared with the control were similar for each of slips, trips and falls, the groups were combined to increase the power to detect significant differences. For the combined intervention groups, the protective effect against the risk of slipping was 0.42 (95\% CI $0.26,0.69)$ and $0.36(0.24,0.54)$ against the risk of tripping. The protective effect against falling was $0.70(0.48,1.01)$. The 95 per cent confidence intervals marginally crossed the null value of one, with a $\mathrm{p}$ value of 0.058 .

\section{COMPARISON WITH HYPOTHETICAL REFERENCE} GROUP

Figures 4, 5 and 6 show Kaplan-Meier survival curves for the combined, the control and hypothetical reference groups for each of slips, trips and falls.

In figure 4, at 360 days (approximately one year post-intervention), the combined intervention groups compared with control achieved a 22 per cent reduction in the probability of slipping. Ninety five per cent confidence intervals for the combined and 


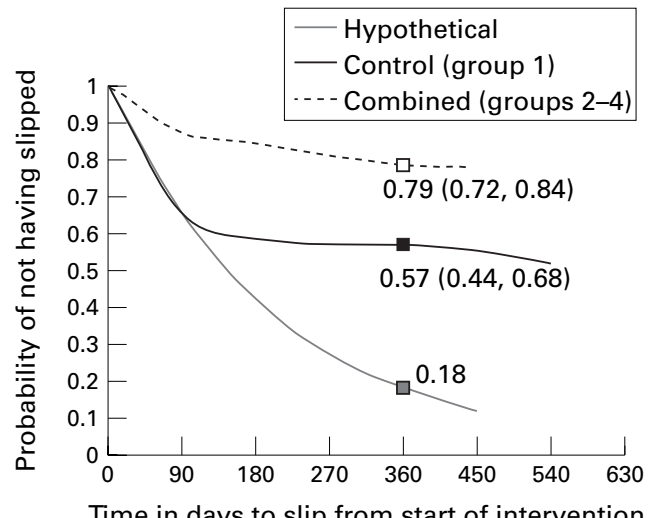

Figure 4 Time to first slip for combined, control and hypothetical groups.

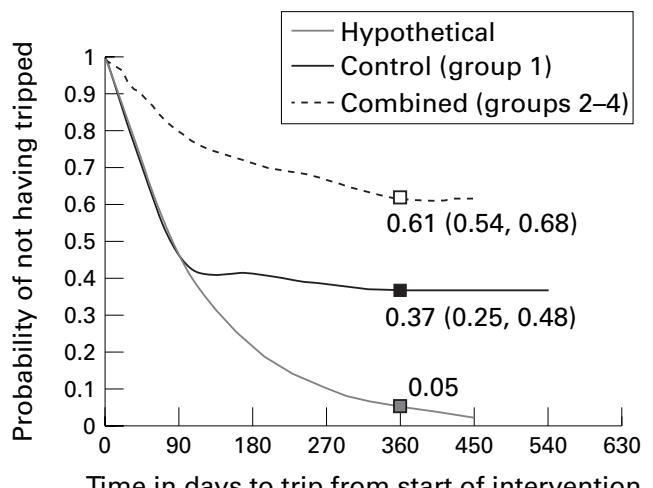

Figure 5 Time to first trip for combined, control and hypothetical groups.

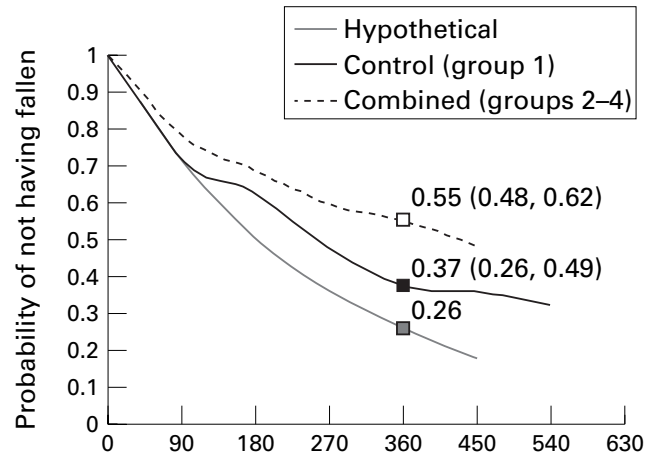

Time in days to fall from start of intervention

Figure 6 . Time to first fall for combined, control and hypothetical groups.

control probabilities $(0.79 ; 0.57$ respectively) did not overlap, nor include the hypothetical probability of 0.18 . Comparing combined intervention group with hypothetical (nonintervened) group showed a possible 61 per cent reduction in probability of slipping.

Similarly in figure 5, at one year postintervention, the reduction in the probability of tripping between combined groups and control was 24 per cent, but increased to a possible 56 per cent between combined intervention and non-intervened groups. Ninety five per cent confidence intervals for the combined and control probabilities $(0.61 ; 0.37$ respectively) did not overlap, nor include the hypothetical probability value of 0.05 .
In figure 6, reduction in the probability of falling at approximately one year postintervention between combined groups and control was 18 per cent, but could have been as high as 29 per cent between combined intervention and non-intervened groups. Ninety five per cent confidence intervals for the combined and control probabilities $(0.55 ; 0.37$ respectively) overlapped slightly. The hypothetical probability of 0.26 was at the lower margin of the confidence interval for the control group $(0.26,0.49)$.

\section{Discussion}

The results show statistically significant reductions in the risk of slips and trips in groups 2, 3 and 4 compared with group 1 (the control), with evidence also for reduction in the risk of falling. The hazard ratios comparing the combined intervention groups with the control indicated a 58 per cent reduction in the risk of slips, a 64 per cent reduction in the risk of trips, and a 30 per cent reduction in the risk of falls. Except for trips, there was no evidence to support the hypothesis that reductions in risk declined with increase in the number of intervention strategies used.

While a reduction in all incidents was attributed to the intervention strategies, it is possible that reducing the incidence of slips and trips is also effective in subsequently reducing falls. This hypothesis would need to be tested in follow up research. If reducing slips and trips had an effect on falls incidence, this would suggest an earlier point of intervention on the postulated continuum of the mechanism of falls.

In addition, the hypothetical model of incidence rates suggested that further significant reductions in the probability of an event were achieved when awareness raising in the control group, specifically through calendar monitoring, was considered an intervention in its own right. Further research is necessary to confirm the effect of diary monitoring on its own as an effective prevention intervention. If confirmed, it has the potential to be a low cost, sustainable strategy for reducing slips, trips and falls among older people, which could be managed by community-based organisations.

\section{COMPARISON WITH OTHER STUDIES}

Randomised controlled trials to reduce falls in community dwelling older people, using multifactorial interventions, have had mixed results. ${ }^{16-19}$ The strongest effect (a $31 \%$ reduction in falls) was reported in the study by Tinetti et $a l,{ }^{16}$ which targeted people at high risk of falls and for whom programme interventions were individually tailored. Falls outcome was prospectively measured using monthly diaries in three of these studies, ${ }^{16-18}$ but the effect of this form of monitoring on the control group was not discussed.

LIMITATIONS OF THE STUDY

The participants were not a random sample of older community dwellers. By virtue of their recruitment through National Seniors Centres, it was expected that they would represent a younger, healthier, more active group, which 
was the focus of the targeted interventions. Compared with population norms for this age group, ${ }^{20}$ the study group had a higher proportion of women and rated their health significantly better than the population as a whole. Because of the differences between the participating group and the general older population, caution needs to be exercised when generalising the results of the study to the wider community of older people.

The self selected group may not be representative of the source population of National Seniors, as the trial group contained a significantly higher proportion of women and over 74 year olds than the National Senior branch population from which it was derived. However, because falls prevention interventions aim to target those at higher risk and can be implemented in a volunteer population only, the results are generalisible to those likely to be recruited through the numerous older people's clubs and groups in Australia.

Groups rather than individuals were randomised to interventions to avoid crossover and for convenience of implementation of intervention strategies. Table 1 showed that differences between groups on the selected risk factors for falls, at baseline, were not statistically significant. Although the groups were not blinded as to intervention or purpose of the study, data collection procedures were the same for each group and telephone follow up of events was made using a standard interview format to minimise bias in reporting and recording outcomes.

\section{IMPLICATIONS}

The study suggests that effective programmes can be introduced at community level to reduce the incidence of slips, trips and falls in well, older community dwellers, particularly through older people's clubs and groups. At 12 month follow up survey of the study group, a majority of participants expressed a high level of satisfaction with the project and reported that the overall effect of involvement had been an increased awareness of falls risk factors and prevention measures. Improved confidence, measured by changes to expressed concern about falling, was also reported. ${ }^{21}$ With over 80 per cent of the group indicating a wish to continue falls monitoring beyond the two year study period, the intervention programme has the potential to capitalise on the older person's motivation to improve their functioning and well being and to be self sustaining with lifelong benefits. Use of available community resources increases the potential cost effectiveness of the interventions.

The support of the National Seniors Association is gratefully acknowledged.

Funding: the project was supported by a grant from the Queensland Health Promotion Council.

Conflicts of interest: none.

1 Tinetti ME, Williams CS. The effect of falls and fall injuries on functioning in community-dwelling older persons. $\mathcal{F}$ Gerontol A Biol Sci Med Sci 1998;53:M112-19.

2 Lord SR, Ward JA, Williams P, et al. An epidemiological study of falls in older community-dwelling women: the Randwick falls and fractures study. Aust F Public Health 1993; 17:240-5.

3 Berg WP, Alessio HM, Mills EM, Tong C. Circumstances and consequences of falls in independent communitydwelling older adults. Age Ageing 1997;26:261-8.

4 Van Beurden E, Kempton A, Sladden T, et al. Designing an evaluation for a multiple-strategy community intervention: the North Coast Stay on Your Feet Program. Aust NZ 7 the North Coast Stay on Your
Public Health 1998;22:115-19.

5 Ryan JW, Dinkel JL, Petrucci K. Near falls incidence: a study of older adults in the community. $\mathcal{f}$ Gerontol Nurs 1993;19:23-8.

6 Lilley JM, Arie T, Chilvers CE. Accidents involving older people: a review of the literature. Age Ageing 1995;24:34665.

7 Myers AH, Young Y, Langlois JA. Prevention of falls in the elderly. Bone 1996;18:87-101S

8 Teno J, Kiel DP, Mor V. Multiple stumbles: a risk factor for alls in community-dwelling elderly. A prospective study. $\mathcal{f}$ Am Geriatr Soc 1990;38:1321-5.

9 Lach HW, Reed AT, Arfken CL, et al. Falls in the elderly: reliability of a classification system. 7 Am Geriatr Soc 1991; 39:197-202.

10 Gillespie LD, Gillespie WJ, Cumming R, et al. Interventions to reduce the incidence of falling in the elderly (Cochrane Review). The Cochrane Library 1998;3:1-32.

11 Connell BR, Wolf SL. Environmental and behavioral circumstances associated with falls at home among healthy
elderly individuals. Arch Phys Med Rehabil 1997;78:17986.

12 Cumming RG, Kelsey JL, Nevitt MC. Methodological issues in the study of frequent and recurrent health problems: falls in the elderly. Ann Epidemiol 1990;1:49-56.

13 Dean AG, Dean JA, Coulombier D, et al. Epi Info, Version 6: a word processing, database and statistics program for public health on IBM-compatible micro-computers. Atlanta, GA: Centres for Disease Control and Prevention, 1995.

14 Peel NM, Cartwright CM, Steinberg MA. Monitoring slips, trips and falls in the older community: preliminary results. Health Promotion fournal of Australia 1998;8:148-50.

15 Cytel Software. EGRET Version 1. Cambridge, MA: Cytel Software Corporation, 1997.

16 Tinetti ME, Baker DI, McAvay G, et al. A multifactorial intervention to reduce the risk of falling among elderly people living in the community. $N$ Engl $\mathcal{F}$ Med 1994;331: people $821-7$.

17 Reinsch S, Macrae P, Lachenbruch PA, et al. Attempts to prevent falls and injury: a prospective community study. Gerontologist 1992;32:450-6.

18 Hornbrook MC, Stevens VJ, Wingfield DJ, et al. Preventing falls among community-dwelling older persons: results from a randomised trial. Gerontologist 1994;34:16-23.

19 Wagner EH, LaCroix AZ, Grothaus L, et al. Preventing disability and falls in older adults: a population-based randomised trial. Am 7 Public Health 1994;84:1800-6. 16th World Congress of Gerontology, Adelaide: 19-23 August, 1997. Canberra: Australian Institute of Health and Welfare, 1997.

21 Steinberg MA, Cartwright CM, Peel NM. No Falls! No Fear! Falls Prevention Project. Report to the Queensland Health Falls Prevention Project. Report to the Queensland Health Promotion Council. Brisbane: Department of Social 